\title{
Performance identification of the asynchronous electric drives by the spectrum of rotor currents
}

Vladimir L. Kodkin, Aleksandr S. Anikin, Aleksandr A. Baldenkov

Department of Theoretical Fundamentals of Electrical Engineering, South Ural State University, Russia

\begin{abstract}
Article Info
Article history:

Received Aug 23, 2018

Revised Oct 9, 2018

Accepted Nov 3, 2018

Keywords:

Frequency control

Rotor current

Slip-ring rotor motor

Spectral analysis

Variable frequency drive

ABSTRACT

The efficiency of analyzing the rotor currents of asynchronous electric drives with frequency control is substantiated in the article. To assess the quality of torque generation in the engine it is suggested to use the spectral analysis of these currents and the fundamental harmonic, as the most accurate "conformity" of slip in an asynchronous motor. The proposed method showed that "sensorless vector" control leads to the appearance of highfrequency harmonics with significant amplitude. Because of these harmonics, a non-sinusoidal electromagnetic moment is created and the performance of the drive is decreased. The most effective method of torque generation is the frequency control with positive stator current feedback. This control is dominated by pronounced harmonic components, which indicates the proximity of this structure to linear and significantly better controllability of the drives, which makes promising their use in high-tech mechanisms, in particular, in industrial robots. Simulation and experiments confirm the proposed theoretical propositions.
\end{abstract}

Copyright @ 2019 Institute of Advanced Engineering and Science. All rights reserved.

\section{Corresponding Author:}

Aleksandr S. Anikin,

Department of Theoretical Fundamentals of Electrical Engineering,

South Ural State University,

76, Lenin prospekt, Chelyabinsk, 454080, Russia.

Email: anikinas@susu.ru

\section{INTRODUCTION}

One of the important assumptions on which methods of describing and analyzing AC motors is based is the assumption of sinusoidal currents of the rotor and stator [1]-[4]. This assumption is made in the derivation of the Closs formula, the construction of vector diagrams, the derivation of vector control and DTC technology (Direct Torque Control) [5]-[12]. The non-sinusoidal nature of these currents is remembered only when analyzing the interference created by electric drives. However, in reality, non-sinusoidal currents greatly reduce the efficiency of asynchronous electric drives, reducing the effective torque.

Examples of the recommended use of Schneider-Electric frequency converters in the rotation mechanisms of tower cranes are known. Operators, trying to apply wind compensation mode, at which they try to start the drive 3-4 times per second, claimed. that the vector-controlled drive "does not have time" to work out the mode, although "old" drives with contactor circuits performed these tasks. These examples were explained by the inexperience of the operators, however, in view of the proposed studies [13], [14], these conclusions should be revised.

\section{PROBLEM DEFINITION}

It is rather difficult to estimate the spectral composition of the stator currents, which are the most accessible in asynchronous electric drives, since in them the predominance of the fundamental (carrier) frequency is very significant [15]-[18]. A short-circuited rotor is not available for measuring currents in it, 
therefore, to identify the processes in an induction motor. The stand with a slip-ring rotor induction motor was created, into whose rotor circuits current sensors were mounted. The schematic diagram of this stand is shown in Figure 1. This stand includes the frequency converter (UZ1), which regulates speed of slip-ring induction motor (M1).The speed data were obtained from an encoder (BR) located on the motor shaft. The stand allows to register synchronous diagrams of rotation speed and rotor currents in static and transient processes, and the software to the digital USB oscilloscope Hantek DSC-2090 (PG) makes it possible to perform spectral analysis of signals, including rotor currents [19], [20].

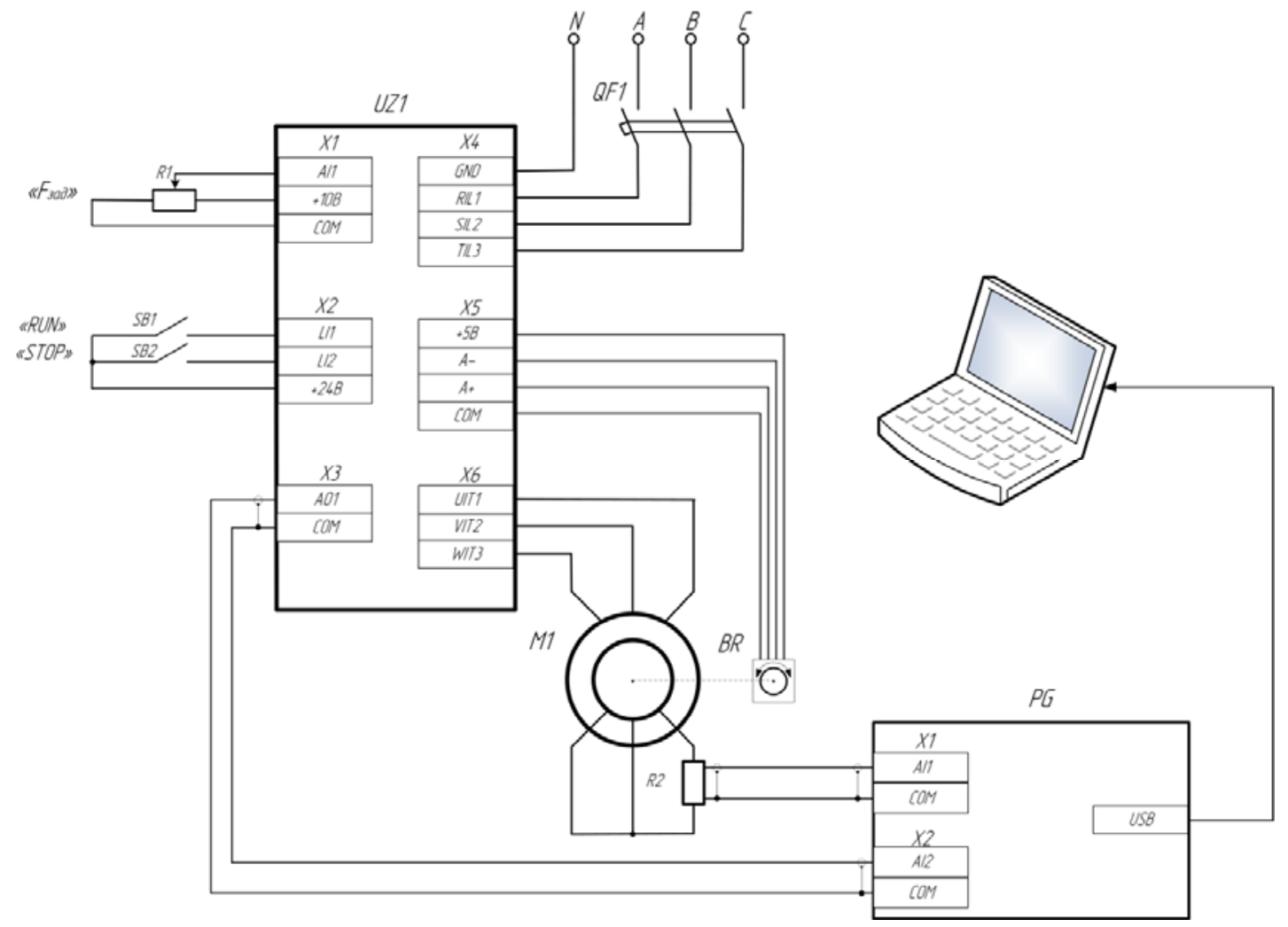

Figure 1. Schematic diagram of the stand

It should be noted that the frequency of the rotor current is very tightly connected with the slip in the motor, i.e. with a discrepancy between the speed of rotation of the electromagnetic field of the stator and the mechanical speed of rotation of the rotor. This discrepancy in the induction motor determines the developed mechanical moment, therefore, in terms of the magnitude of the slip or the frequency of the rotor current, it is possible to estimate the efficiency of the formation of a mechanical moment with this or that control method. It is very difficult to estimate the real slip in a drive with a frequency converter. The point is that with vector control and with the corrected scalar, the stator voltage frequency changes. Therefore, even if the speed of rotation exactly corresponds to the preset, the actual slip, i.e. the mismatch between the rotational speed of the electromagnetic field of the stator and the mechanical speed of the rotor can take any values. Consequently, the efficiency of the method of torque generation is higher, the smaller the slip required for a given moment. And best of all, the real slip is estimated by the rotary current frequency.

\section{EXPERIMENTAL RESEARCH}

Similar results were obtained in experimental studies on a laboratory bench. Figures 2-5 show the time diagrams of the rotor currents at idle and under the same load close to the nominal one, as well as spectra indicating the main frequencies of the rotor currents [21], [22]. The values of the fundamental frequencies under load and no-load are shown in Table 1.

Int J Pow Elec \& Dri Syst, Vol. 10, No. 1, March 2019 : 211 - 218 

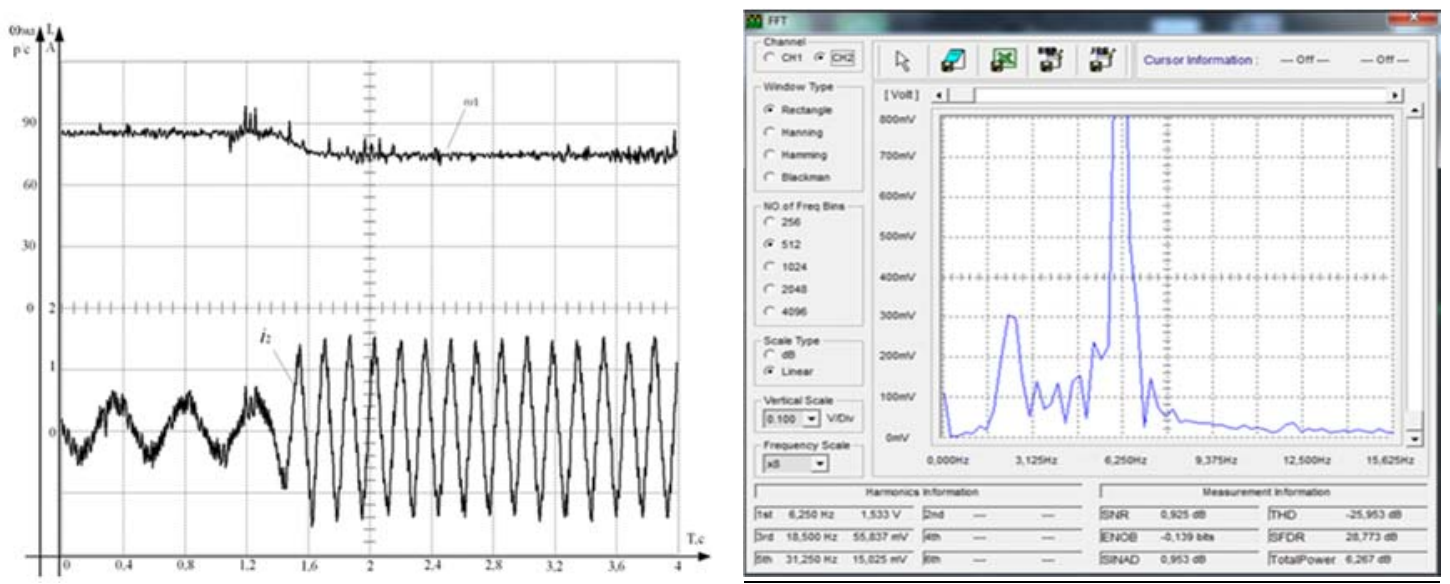

Figure 2. The diagram of the speed and current of the rotor of an asynchronous drive with vector control. Spectrum of the rotor current signal
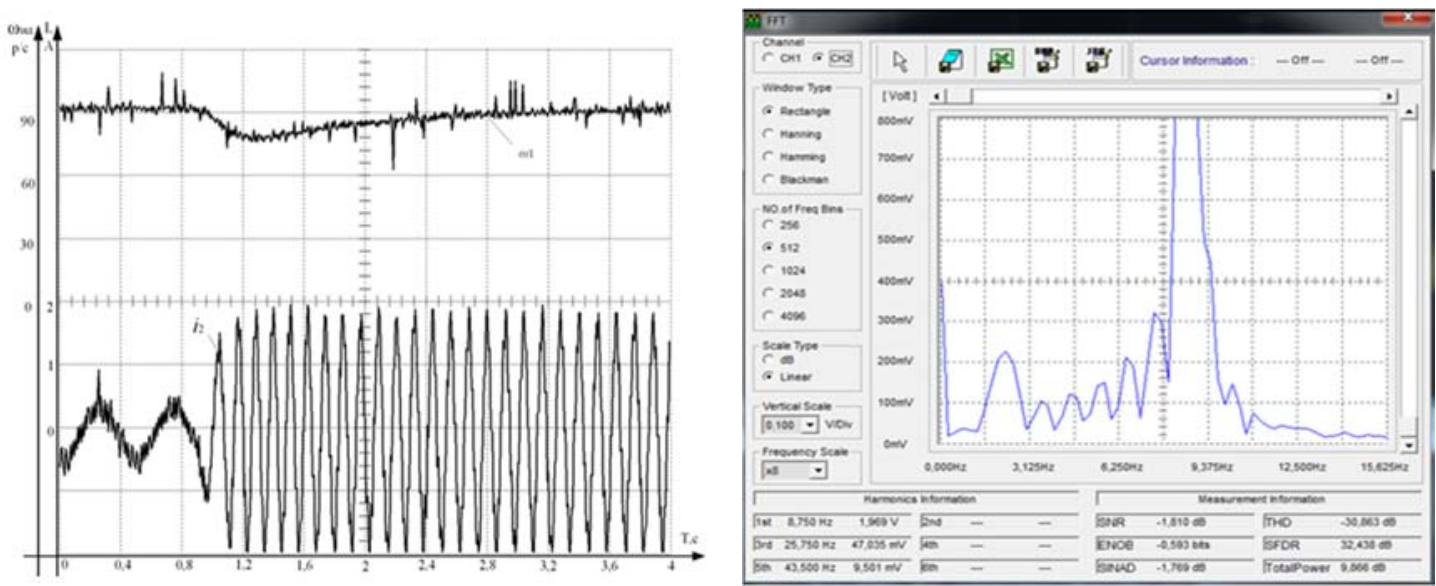

Figure 3. The diagram of the speed and current of the rotor of an asynchronous drive with closed-loop vector control. Spectrum of the rotor current signal
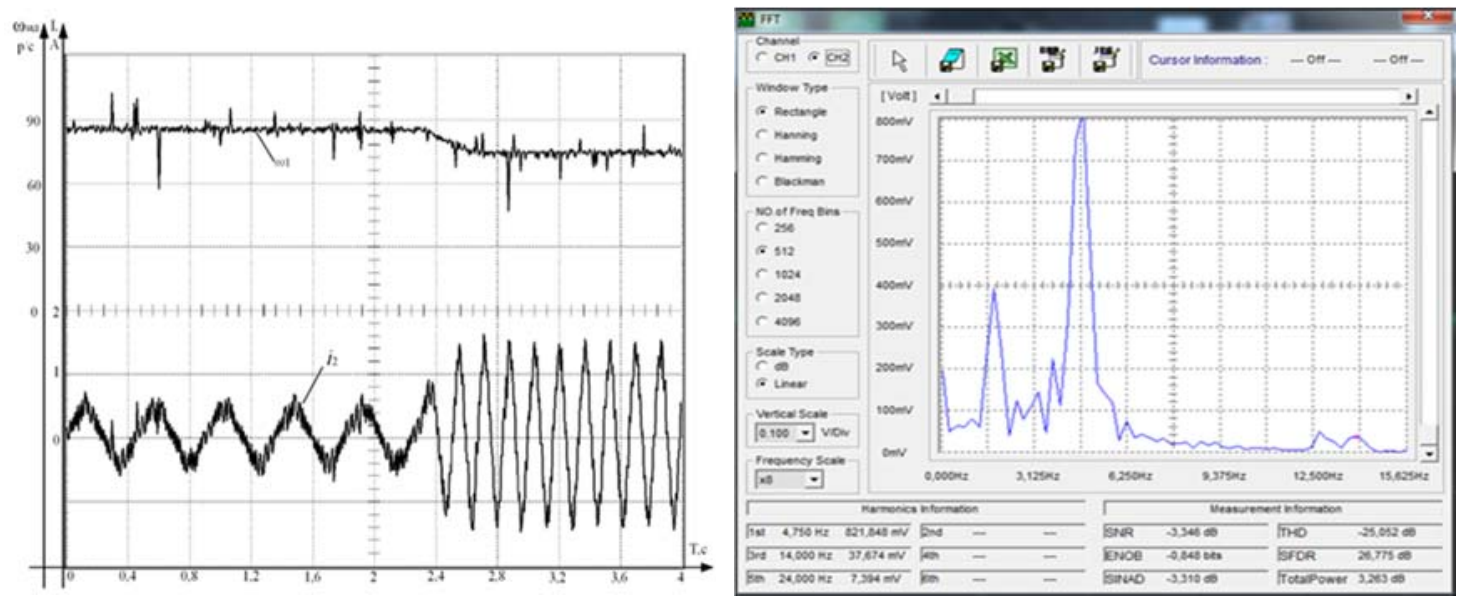

Figure 4. Diagram of the speed and current of the rotor of an asynchronous drive with scalar control. Spectrum of the rotor current signal 

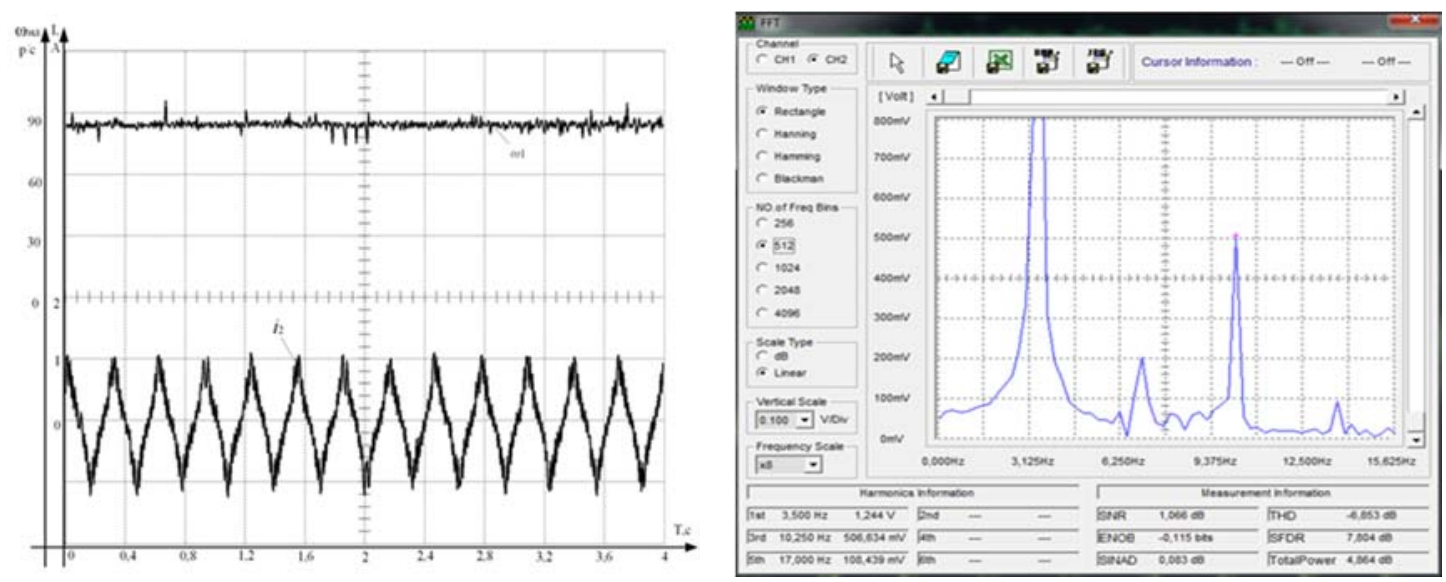

Figure 5. Diagram of the speed and current of the rotor of an asynchronous drive with scalar control and stator current feedback. Spectrum of the rotor current signal

Table 1. The values of the fundamental frequencies of the rotor currents under load and at no-load

\begin{tabular}{ccc}
\hline Control system & no-load & under load \\
\hline Vector control & $2,1 \mathrm{~Hz}$ & $6,25 \mathrm{~Hz}$ \\
Vector speed feedback control & $2,1 \mathrm{~Hz}$ & $8,75 \mathrm{~Hz}$ \\
Scalar control without feedback & $1,69 \mathrm{~Hz}$ & $4,75 \mathrm{~Hz}$ \\
Scalar control with stator current feedback & $1,75 \mathrm{~Hz}$ & $3,5 \mathrm{~Hz}$ \\
\hline
\end{tabular}

Analysis of the spectra of rotor currents convincingly shows that the formation of the necessary torque in a vector-controlled electric drive, even when the speed loop is closed, is not the most effective, thereason for this is probably the presence of significant harmonics at a frequency of 3 to $8 \mathrm{~Hz}$ as shown in Figures 2 and 3.Attention should be drawn to Figure 3, vector control with feedback on the engine's rotation speed, after the load is thrown and the speed failure, the regulator "pulls" it, but the rotor current frequency does not change, which is indicative not of the efficiency of the torque generation algorithm for vector control, but about an increase in the frequency of the stator voltage. It is this structure that is implemented in the drive control scheme of the turn of the tower crane, which was mentioned in the introduction. The exceptionally "tightened" load parrying process is associated with insufficient torque and does not allow for the "quick" start-up modes of the turn actuator required for wind retarding attempts. And it should be recognized as "guilty" in this situation, an insufficient "understanding", especially the nonlinearities of an asynchronous electric drive.

To explain these results, remaining within the assumptions made at the beginning of the article about the sinusoidal current of the rotor and the stator of an asynchronous electric motor under frequency control, is very difficult. Having considered the spectra of rotor currents, one can make the assumption of the presence of a much larger spectral composition of the rotor currents (and, consequently, of the stator currents) under vector control than in the case of a scalar one. It is very difficult to estimate the influence on the torque of these "harmful" harmonics by direct spectral analysis. But, estimating the fundamental harmonic of the rotor current, which corresponds to real slip, i.e. mismatch of the rotational speed of the stator field and mechanical rotation of the rotor, it can be concluded that the torque generation efficiency is effective for each of the considered control methods for an asynchronous motor (vector, scalar and scalar with dynamic positive stator current coupling). The results of the experiments as a whole coincide with the results of the experiments carried out earlier, but they contradict the generally accepted ideas.

\section{MODELING PROCESSES IN AN ASYNCHRONOUS DRIVE}

Moreover, before the creation of the stand, the model of the electric drive based on the induction motor and the frequency converter with vector control was carried out. In Figure 6 is showed the scheme of the AC drives compiled in the Simulink application of the MATLAB software environment, and Figure 7 shows the block of the vector control system.

Int J Pow Elec \& Dri Syst, Vol. 10, No. 1, March 2019: $211-218$ 


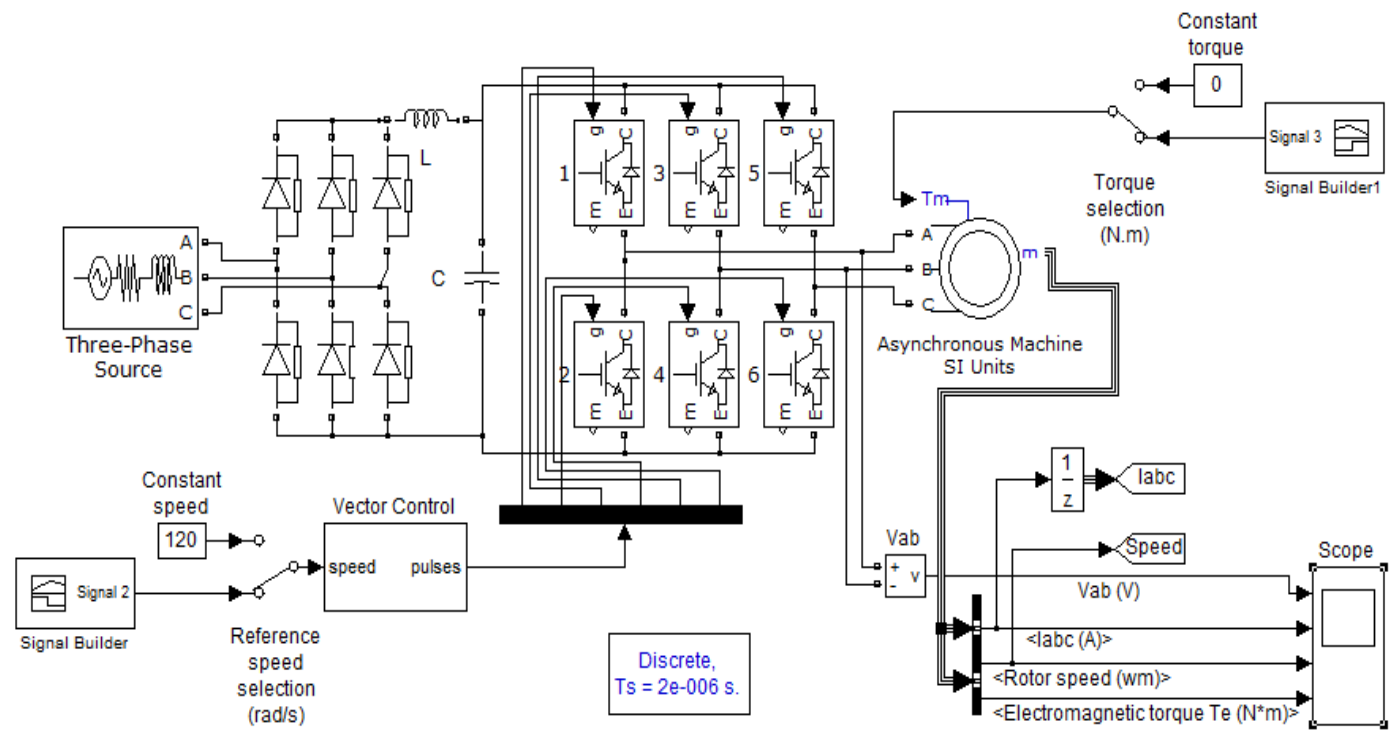

Figure 6. The model of AC drives with vector control

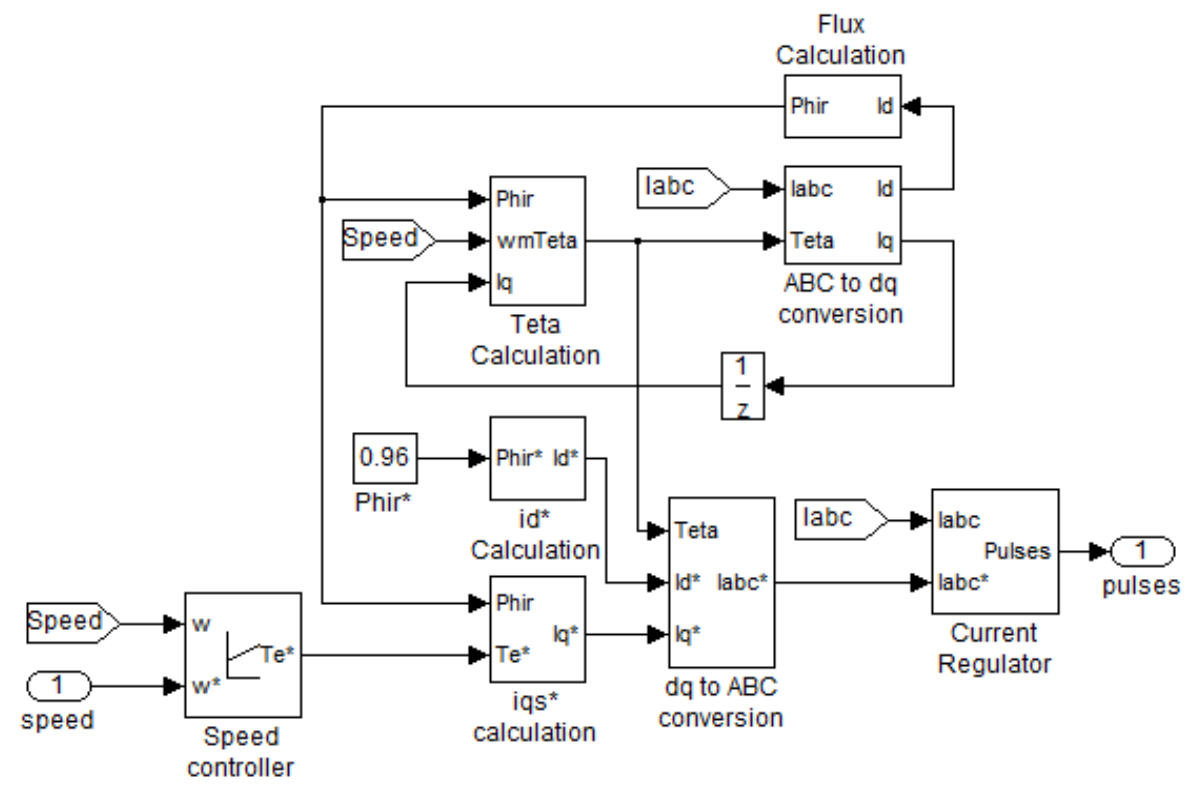

Figure 7. The "Vector control" block

The experiments were carried out in the following way: successive acceleration at idle speed to 10 , 20, 30, 40 and $50 \mathrm{~Hz}$ and a load drop at each frequency reference. The load was set by stepwise action equal to the nominal value of the motor torque. In Figure 8 shows the results of simulation of acceleration and load sketches at different speeds of rotation under vector control, in Figure 9 - with scalar without feedback, in Figure 10 - with scalar control with positive feedback on the stator current. 


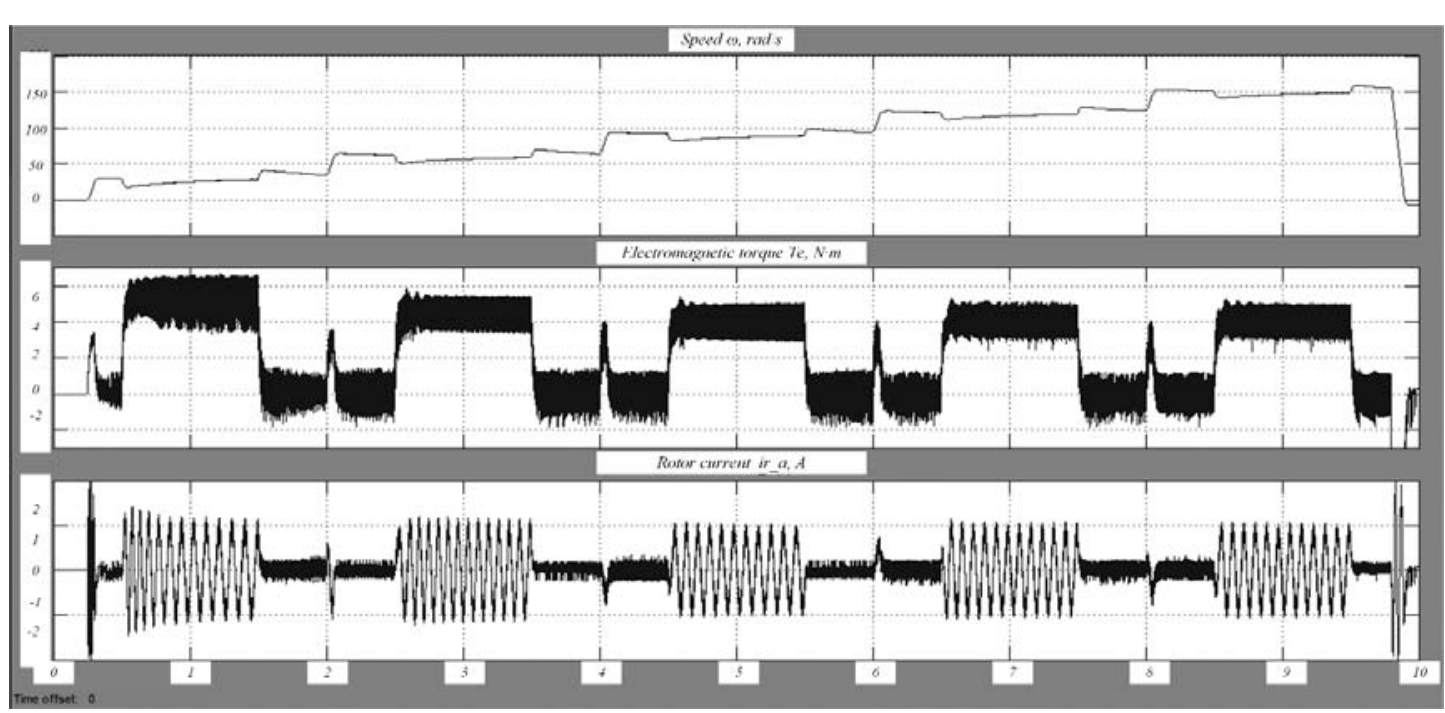

Figure 8. Modelling processes in an asynchronous electric drive with vector control system

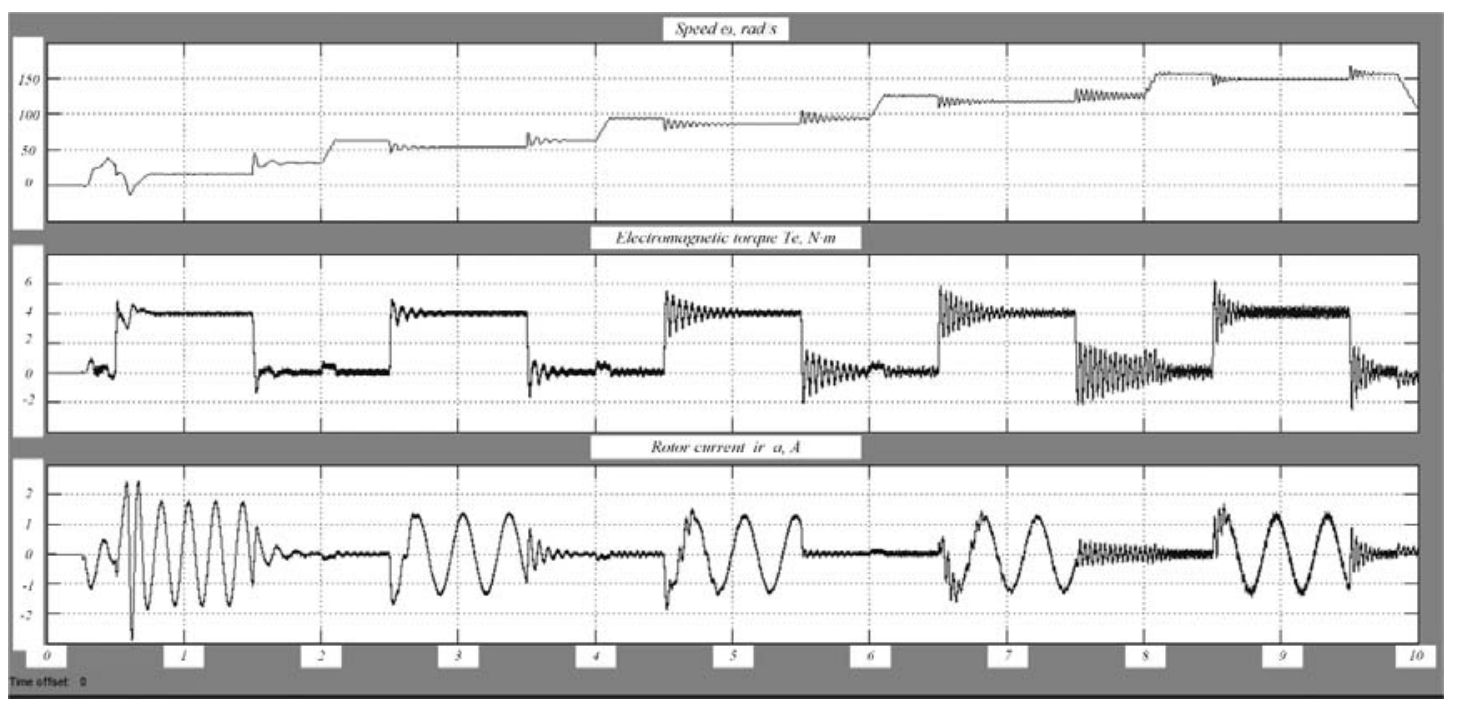

Figure 9. Modelling processes in an asynchronous electric drive with scalar control without feedback

The frequency of the rotor current under load (at a speed of $90 \mathrm{rad} / \mathrm{s}$ ) with vector control is $10.6 \mathrm{~Hz}$, scalar without feedback $-2.72 \mathrm{~Hz}$, scalar with feedback on the stator current $-1.74 \mathrm{~Hz}$.It is obvious that the frequency of the rotor currents is the lowest in the model of the system with a positive feedback on the stator current, while working at low speeds is stabilized in comparison with scalar control and, in practice, there are no speed dips in the load sketches, and in comparison with the vector one - significantly smaller frequency of the rotor current and, accordingly, real slip [13], [23], [24].

The frequency of the rotor currents is the lowest in the model of the system with a positive feedback on the stator current, which indicates a more efficient algorithm for the formation of a mechanical moment. At that, in comparison with the scalar control in an electric drive with a positive stator current connection, work at low speeds is stabilized and, in practice, there are no speed dips in the case of load surges, and in comparison with the vector there are significantly lower frequencies of the rotor current and, accordingly, the frequency of real slip. Analytic way to explain and, even more so. to predict this situation is almost impossible, so let's turn to experiments. 


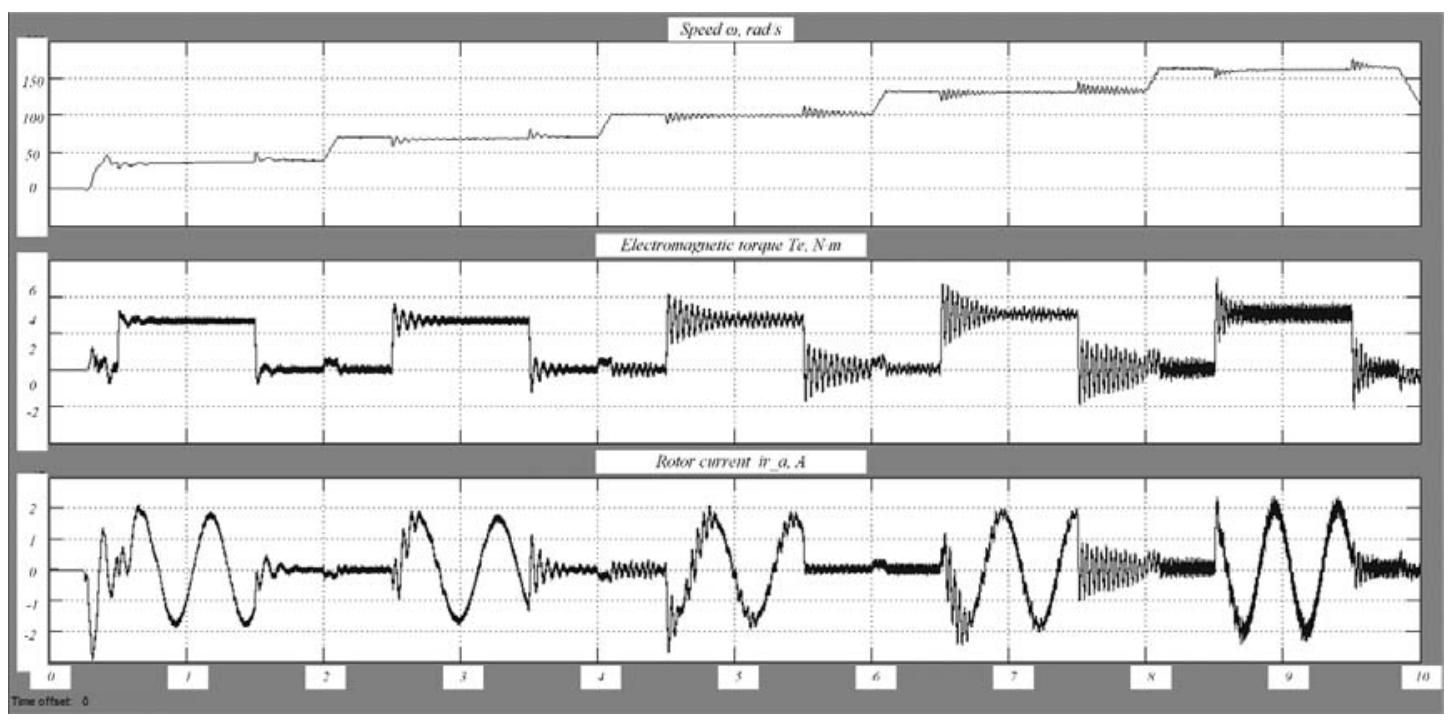

Figure 10. Modelling processes in an asynchronous electric drive with scalar control with feedback on the stator current

\section{CONCLUSIONS}

Thus, the spectral analysis of the rotor currents of an asynchronous electric drive has shown that the most effective method of torque generation will be frequency control with positive stator current feedback.

As the spectral analysis shows, this control is dominated by pronounced harmonic components, which indicates the proximity of this structure to linear and significantly better controllability of the drives, which makes promising their use in high-tech mechanisms, in particular, in industrial robots.

\section{REFERENCES}

[1] Usoltsev, A.A, "Vector control of asynchronous motors," Tutorial. - Spb.: ITMO, 120 p, 2002. $\mathrm{http}: / /$ servomotors.ru/documentation/frequency_control_of_asynchronous_motors/chastupr.pdf

[2] Pozdeev, A.D, "Electromagnetic and electromechanical processes in frequency-controlled asynchronous electric drives," - Cheboksary: Publishing house Chuvash University, 172 p, 1998.

[3] Sokolovsky, G.G. AC electric drives with frequency control. - Moscow: "ACADEMIA", 267 p, 2006.

[4] Srinivas Gangishetti, Tarakalyani Sandipamu, "Different Control Schemes for Sensor Less Vector Control of Induction Motor," International Journal of Power Electronics and Drive System (IJPEDS), Vol. 8, No. 2, pp. 712 721, June 2017.

[5] Kodkin V. L., Anikin A. S, "Frequency control of asynchronous electric drives in transport," 2015 International Siberian Conference on Control and Communications (SIBCON), 2015.

[6] V.L. Kodkin, A.S. Anikin, Ya. A, "Shmarin Effective Frequency Control for Induction Electric Drives under Overloading," Russian Electrical Engineering, Vol. 85, No. 10, pp. 641-644, 2014.

[7] Park R., Robertson B., "The reactances of synchronous machines,” Tr. AIEE,vol. 47, 1928.

[8] Md. Rashedul Islam, Md. Maruful Islam, Md. Kamal Hossain, "Pintu Kumar Sadhu Performance Analysis of a DTC and SVM Based Field-Orientation Control Induction Motor Drive," International Journal of Power Electronics and Drive System (IJPEDS), Vol. 5, No. 3, pp. 336 343, February 2015.

[9] Shevchenko, A.F. and Abdel' Maksud Selim, S.A., "Vector control of stator's current in synchronous motor with permanent magnets for drowned pump drive," Nauchn. Vestn. Novosib. Gos. Tekhn. Univ., no. 2(43), 2011.

[10] Yahya Ahmed Alamri, Nik Rumzi Nik Idris, Ibrahim Mohd. Alsofyani, Tole Sutikno, "Improved Stator Flux Estimation for Direct Torque Control of Induction Motor Drives," International Journal of Power Electronics and Drive System (IJPEDS), Vol. 7, No. 4, pp. 1049 1060, December 2016.

[11] Kodkin V.L, "Problems of introducing frequency regulation in the mining industry / V.L. Kodkin, M.A. Malcher, A.S. Anikin," Bulletin of SUSU. series "Energy". Issue. 18. - No. 37 (296). - P. 154, 2012.

[12] M. Jannati, N. R. N. Idris, and M. J. A. Aziz, "Speed Sensorless Fault-Tolerant Drive System of 3-Phase Induction Motor Using Switching Extended Kalman Filter" TELKOMNIKA Indonesian Journal of Electrical Engineering, vol. 12, 2014.

[13] Kodkin V.L, "Experimental Research of Asynchronous Electric Drive with Positive Dynamic Feedback on Stator Current," III International Conference on Industrial Engineering, Applications and Manufacturing, ICIEAM 2017 - Proceedings, 2017. 
[14] V.L. Kodkin, A.S. Anikin, Ya.A. Shmarin, "Dynamic Load Disturbance Correction for Alternative Current Electric Drives," II International Conference on Industrial Engineering, Applications and Manufacturing, ICIEAM 2016 Proceedings, 2017.

[15] Vorob'ev, N.N, Theory of series, 4 ed., Revised. And additional. - Moscow: Science, 408 p, 1979.

[16] Bonar D.D., Khoury M.J., "Real Infinite Series," The Mathematical Association of America, 274 p., 2006.

[17] Mejlbro L, "Fourier Series and Systems of Differential Equations and Eigenvalue Problems: Guidelines for Solutions of Problems," Leif Mejlbro \& Ventus Publishing Aps, 125 p, 2007.

[18] Loday-Richaud M., "Divergent Series, Summability and Resurgence II. Simple and Multiple Summability," Springer International Publishing, 272 p, 2016.

[19] Anikin A.S. Dynamic positive coupling in asynchronous electric drives with frequency control / A.C. Anikin, V.L. Kodkin, A.A. Baldenkov // "Priorities of world science: experiment and scientific discussion" Materials of the 8th international scientific conference. Scientific and Publishing Center "Otkrytie". North Charleston, SC, USA, 17-18. - P.119-124, June 2015.

[20] V.L. Kodkin, Ya.A. Shmarin, A.S. Anikin, AA Baldenkov, N.A. Loginova, "Correction of dynamic moment perturbations in electric drives of alternating current" Science of SUSU. Materials of the 68th scientific conference, pp 805-814, 2016.

[21] V.L. Kodkin, A.S. Anikin, A.A. Baldenkov, "Spectral Analysis of Rotor Currents in Frequency-controlled Electric Drives," 2nd International Conference on Automation, Mechanical and Electrical Engineering, AMEE 2017 Proceedings. -2017

[22] V.L. Kodkin, A.S. Anikin, A.A. Baldenkov, "The analysis of the quality of the frequency control of induction motor carried out on the basis of the processes in the rotor circuit," XI International Scientific and Technical Conference "Dynamics of Systems, Mechanisms and Machines" - Proceedings - 2017.Omsk, 14-16.11.2017

[23] Kodkin. V.L, "Methods of optimizing the speed and accuracy of optical complex guidance systems based on equivalence of automatic control system domain of attraction and unconditional stability of their equivalent circuits," Proceedings of SPIE - The International Society for Optical Engineering. - 2016

[24] V.L. Kodkin, A.S. Anikin, A.A. Baldenkov, "Analysis of stability of electric drives as non-linear systems according to Popov criterion adjusted to amplitude and phase frequency characteristics of its elements," 2nd International Conference on Applied Mathematics, Simulation, and Modeling AMSM 2017 - Proceedings. - 2017

Int J Pow Elec \& Dri Syst, Vol. 10, No. 1, March 2019: $211-218$ 